\title{
Shear Stress Biology of the Endothelium
}

\author{
Peter F. DAVIES, ${ }^{1}$ Jos. A. SPAAN, ${ }^{2}$ and Robert KRAMS ${ }^{3}$ \\ ${ }^{1}$ Institute for Medicine and Engineering, University of Pennsylvania, Philadelphia, PA 19104; ${ }^{2}$ Department of Medical Physics, Faculty \\ of Medicine, University of Amsterdam, Amsterdam, Netherlands; and ${ }^{3}$ University of Rotterdam, Rotterdam, Netherlands
}

(Received 3 April 2005; accepted 3 June 2005)

\begin{abstract}
The relationships between blood flow, mechanotransduction, and the localization of arterial lesions can now be advanced by the incorporation of new technologies and the refinement of existing methods in imaging modalities, computational modeling, fluid dynamics, and high throughput genomics and proteomics. When combined with traditional cell and molecular technologies, a powerful palette of investigative approaches is available to address shear stress biology of the endothelium at levels extending from nanoscale subcellular detailed mechanistic responses through to higher organizational levels of regional endothelial phenotypes and heterogeneous vascular beds.
\end{abstract}

Keywords-Mechanotransduction, Biomechanics, High throughput analyses, Atherosclerosis, Vascular biology

\section{INTRODUCTION}

The vessel wall reacts to multiple chemical and mechanical stimuli in the flowing blood; the mechanical factors are principally pressure and shear stress. These responses often function in a feedback manner either to control blood flow or adapt the vessel structure to its required function. ${ }^{7,19,54}$ The general health of the vessel wall is dependent on the shear that it experiences via the endothelial interface and the resulting mechanosensing mechanisms of the endothelial cells. ${ }^{9}$ This position paper is focused on the blood flow-vessel wall interactions related to shear.

Interest in shear stress biology of the endothelium is principally directed to three related objectives: (i) understanding the function of shear in integrated vascular physiology, particularly in resistance vessels and arterial remodeling, (ii) a detailed understanding of the cellular mechanisms by which shear stress influences endothelial biology at multiple levels, mostly physiological, and (iii) an understanding of the relationships between hemodynamic forces and the localization of atherosclerosis, a disorder in which the endothelium plays a critical pathogenic role.

Address correspondence to Peter F. Davies, Institute for Medicine and Engineering, University of Pennsylvania, Philadelphia, PA 19104. Electronic mail: pfd@pobox.upenn.edu

\section{SHEAR STRESS AND PHYSIOLOGICAL RESPONSES}

That increasing blood flow through arteries results in vasodilation was first observed in larger arteries in $1933 .{ }^{47}$ However, it was more than 50 years later that the role of the endothelium in this response was established by varying the viscosity of perfusion medium in isolated artery preparations thereby demonstrating that shear stress was an important factor. ${ }^{29,31,41}$ The isolated perfused resistance artery preparation became important in quantifying these acute responses as a function of vessel diameter and its interaction with spontaneous or induced myogenic tone. ${ }^{34}$ It is thought that shear-induced mediation is important in organ flow control since it amplifies the dilatory stimulus of the smallest arterioles due to the larger more proximal ones. ${ }^{7}$ Furthermore, wall shear stress has been implicated in the development and adaptation of vascular beds, ${ }^{30,38}$ and in the chronic physiological remodeling of large arteries ${ }^{20}$ where the presence of the endothelium determines the outcome..$^{35}$ Although theoretical and experimental studies ${ }^{1,43}$ implicate shear as only one of the determinants of vascular adaptation, ${ }^{23,44}$ the endothelium clearly plays a central role, and its relationship to shear stress needs to be understood.

\section{SHEAR STRESS ENDOTHELIAL MECHANOTRANSDUCTION}

The investigation of shear stress relationships to the endothelium in vitro is now a mature field that began shortly after the successful sustained culture of differentiated endothelial cells when flow devices used in fluid dynamics research were seeded with an endothelial lining. ${ }^{15}$ Easy access to the cells and ready manipulation of the flow characteristics provided descriptions of morphological and cytoskeletal changes and the development of simple computational analyses of the changes, ${ }^{36,45}$ calculations of flow characteristics and shear stresses were based on classical fluid dynamics. Subsequently, the averaged cellular responses of monolayers of cultured cells were measured ${ }^{10,11,48}$ which led to the detailed probing of single living cells ${ }^{14,26,39}$ including computational measurements 
using sophisticated techniques, e.g. surface topography, cytoskeletal protein dynamics, and more recently an appreciation of the potentially important role of the luminal glycocalyx, a carbohydrate-rich surface coat consisting of the ectodomains of glycoproteins and proteoglycans. ${ }^{6,50,56}$ Better definition of the actual sites of initial interactions between shear and the cell has extended the force-cell relationship beyond the surface structures into the interior of the cell. This has led to an improved understanding of mechanotransmission throughout the cytoskeleton and the development of intracellular strain maps. ${ }^{25}$ From spatial images of adhesion sites, junctions, and cytoskeletal dynamics a decentralized view of mechanotransduction has evolved ${ }^{4}$ that has been confirmed by sophisticated molecular probing of discrete subcellular locations (e.g., Ref. 49). However, spatial mapping of cellular biomechanics and the temporal relationships remain poorly understood. Advances in cell and molecular imaging, metabolic markers and other probes, provide great opportunities to correct this deficit.

\section{SHEAR STRESS ENDOTHELIAL BIOLOGY AND ATHEROSCLEROSIS}

It is a longstanding observation that atherosclerosis is not evenly distributed over the arterial system. A few decades ago both high and low shear stress were postulated as an explanation for this uneven distribution of atherosclerosis ${ }^{4,16,17}$ coincidental with the unequivocal demonstration of the retention of endothelium during atherogenesis, ${ }^{13}$ a finding that first implicated endothelial functional phenotype as a critical factor in the shift from normal physiology to flow-directed focal pathology. Since then, evidence supporting average low shear stress as a plaque-modulating factor ${ }^{21,32,33,53,55,58}$ has accumulated although the complex flow characteristics in these regions may be as important as the average magnitude of the stress per se. ${ }^{10}$ Based upon these observations, several rheological theories have been postulated, including dispersion of LDL particles towards the vessel wall, ${ }^{57}$ shear-dependent accumulation of inflammatory cells ${ }^{27,28}$ and shear stress dependent gene expression of the endothelial cell. ${ }^{22,37,46}$ The last theory is receiving attention with focused efforts to dissect cellular biomechanical mechanisms during the past decade (briefly noted above) have been assisted by developments in molecular genetics that permit localized endothelial analyses (vascular bed and regional profiles) to be addressed. Developments include the functional analysis of the consequences of genetic manipulation in intact mammals through gene knock-out and transgenic methods, ${ }^{8,51}$ the measurement of candidate genes in situ, ${ }^{14,24}$ the development of high throughput arrays that facilitate profiling of endothelial phenotypes in vitro, ${ }^{3,5,18,52}$ and recently, phenotype profiles in highly localized regions of arteries in vivo, ${ }^{40}$ the latter following refinements of RNA amplification methods to improve the fidelity of differential gene expression. ${ }^{42}$ These approaches are suited to detailed 'global' investigations of detailed pathways of shear stress transmission and mechanotransduction in the endothelial cell and the important mapping of endothelial biology and pathology in relation to atherogenesis. However, it is essential that well-designed statistics and bioinformatics are used in microarray studies in accordance with fast-developing international standards. ${ }^{2}$ There are now great opportunities to apply a range of length scales to investigate shear stress endothelial mechanotransduction leading to convergence ${ }^{12}$ of the regional behaviour of endothelium in vivo with the detailed cellular and molecular responses in single living cells in real time at nanoscale resolution.

\section{FUTURE DIRECTIONS}

Present and future approaches are limited only by the imagination of the investigator; however, from a careful review of the literature we propose several broad priority objectives (not in any order):

- Adapt the latest technologies to the problem wherever possible by direct analyses of cells in situ, in vivo, or obtained immediately post mortem, i.e. retaining some characteristics of the native vascular environment.

- Design in vitro experiments that critically test the most dominant fluid dynamics characteristics that exist in vivo and test the conclusions by experiments in vivo or in intact tissues.

- Embrace the use of high throughput genomics and proteomics that simultaneously measure many variables from the same biological source to provide an integrated profile of cellular behavior. The technologies are applicable to smaller groups of cells and will eventually allow measurement of gene expression profiles of single endothelial cells in vivo and for cells in vitro for which computational and image-based information will be simultaneously gathered.

- Measure the local biomechanical environment at the maximum resolution appropriate to the system. Detailed knowledge of cellular geometry and structure is required. Approaches may include imaging of cell surface (e.g., AFM, TIRF), cytoskeleton (GFP and similar endogenous reporters), adhesion dynamics, subcellular localization of signaling molecules etc. Some of these measurements permit detailed, high resolution computation of localized stress concentrations (surface, cytoskeleton).

- Further develop cytomechanics in the living endothelial cell both in vitro and in vivo. Since structures ranging from the glycocalyx to the basal adhesion proteins are interconnected, mechanotransmission needs to be addressed by classical engineering to allow better interpretation of the biological responses, many of which are spatially accessible using molecular tags. This is an area where the biology is ahead of the mechanics. 
- Prioritize spatial and temporal relationships when measuring force characteristics and cellular responses. The deformation of structural components needs to be measured as a function of time and space, and in relationship to the timing of biological signals. Confocal and deconvolution microscopy are particularly useful for 3-D and 4-D image reconstructions with $z$-resolution approaching $100 \mathrm{~nm}$.

- Determine the importance of gradients of shear stress on endothelial biology and the temporal changes occuring throughout the cardiac cycle. All endothelium is subjected to cyclical shear stress. In most cases it is directional; in flow separation regions it is multidirectional, multi frequency, and momentarily zero. How does the cell filter these constantly changing stimuli?

- Incorporate other biomechanical and cellular interactions into the shear stress biology of the endothelium. A better understanding of non-shear components of vascular hemodynamics and their integration into current "dogmas' would include other biophysical parameters of the blood vessel, e.g. diffusion and convective transport particularly in the glycocalyx, slip/non-slip conditions, the influence of hemodynamic pressure variables on smooth muscle cells communicating with the endothelium, etc.

- A detailed structural, dynamic, genetic, and functional analysis of the glycocalyx is required to better understand the initial contact of flowing plasma and the endothelial cell surface. Both mechanical deformation and transport characteristics are important considerations at this site.

- Investigate the shear stress biology of the endothelium in relation to atherogenesis over a range of length scales using both high throughput and single probe technologies, and with an emphasis on in vivo studies. Recent advances in nucleic acid amplification permit regional endothelial phenotyping in vivo, and single probe techniques for candidate gene expression provide high resolution spatial information in situ.

- Study other important physiological and pathological mechanisms in which shear stress is a factor, e.g. for the adhesion, rolling and arrest of immunocompetent cells at the endothelial surface; the expression of adhesion factors and force interactions between cells and proteins. Neovascularization is coupled to shear stress by angiogenesis and all shear stress related genes are now producing proteins from these vessels. Shear stress is strongly emerging as an important determinant of cardiac development.

- We recognize important links with the wider field of vascular biology, particularly in smaller arterial vessels. The stresses and strains of the intracellular skeleton induced by shear stress must bear a relation with those induced by other causes of cellular shape changes; for example during smooth muscle-regulated changes of vessel diameter, an event which also inevitably alters the shear stresses. There is evidence that pressure as well as shear is a factor in vascular remodeling.

- Biofluid mechanics is undergoing recognition as an important component of many physiological and pathological processes and is therefore gaining interest and acceptance in many biomedical and clinical research areas. Most topically, they include cardiology (molecular and interventional), pathology, developmental biology, cell and molecular biology, and new avenues of interest in cancer biology and genetics. Biofluid dynamics will play a role in interventional cardiology as emerging techniques that enable the calculation of shear stress fields in relation to plaque characteristics in patients become available.

\section{BIOFLUID MECHANICS AND THE NIH ROADMAP}

The successful implementation of biofluid mechanics research requires the integrated efforts of investigators who usually have primary training in different disciplines and fields. There are many examples of successful collaborations between the biophysical, bioengineering, biomedicine, and clinical communities. However, the recent NIH Roadmap demands the formalized development of interdisciplinary teams focused upon defined objectives that require collaborative efforts from multiple fields. It is likely that other countries will adapt a similar strategy.

There are two initial approaches to the long-term successful implementation of strategic planning for research directed to these new pathways of discovery: (i) entice established faculty in different disciplines to collaborate by incentives (funding); (ii) introduce and sustain interdisciplinary training early in the careers of students without compromising depth and rigour in a primary discipline. The NIH Roadmap proposes both approaches and in addition redefines the role of universities by encouraging centers of technical excellence (in addition to intellectual excellence), a role traditionally maintained by government (e.g., NIH, CDC, etc), Institutes of Technology, and contracts to the private sector.

In the US, biofluid mechanics research is positioned to attract (additional) NIH funding by virtue of the interdisciplinary nature of the subject. It will be necessary to overcome infrastructural barriers in US universities that obstruct some aspects of cooperation between faculty in disparate departments and schools which are competing for common resources, even within interdisciplinary departments such as biomedical engineering. The availability of NIH funding targeted to support interdisciplinary collaborations across departments (and institutions) will help in this regard as does the establishment of formal interdisciplinary supradepartmental groupings (institutes, centers) at some universities. Common to all countries is a needed attitudinal change in the traditional cultural differences that exist 
between enginnering and medical departments, and the sustained education of young people in an interdisciplinary culture that promises a clear career pathway; in the US, biomedical engineering departments and interdisciplinary Centers are perhaps the most appropriate structures to do this. The academic infrastructure varies from country to country; in smaller countries with geographically closely located institutions and smaller budgets, such centers may interfere with other funding priorities. Whatever the country or infrastructure, it is in the interests of Biofluid Mechanics investigators to support such developments.

\section{REFERENCES}

${ }^{1}$ Bakker, E. N., J. P. Versluis, P. Sipkema, J. W. VanTeeffelen, T. M. Rolf, J. A. Spaan, and E. VanBavel. Differential structural adaptation to haemodynamics along single rat cremaster arterioles. J. Physiol. 548:549-555, 2003.

${ }^{2}$ Brazma, A., P. Hingamp, J. Quackenbush, G. Sherlock, P. Spellman, C. Stoeckert, J. Aach, W. Ansorge, C. A. Ball, H. C. Causton, P. Glenisson, F. C. P. Holstege, I. F. Kim, V. Markowitz, J. C. Matese, A. Robinson, U. Sarkans, J. Stewart, R. Taylor, J. Vilo, and M. Vingron. Minimum information about a microarray experiment - MIAME - towards standards for microarray data. Nat. Genet. 29:365-371, 2001.

${ }^{3}$ Brooks, A. R., P. I. Lelkes, and G. M. Rubanyi. Gene expression profiling of human aortic endothelial cells exposed to disturbed flow and steady laminar flow. Physiol. Genomics 9:27-41, 2002. ${ }^{4}$ Caro, C. G., J. M. Fitzgerald, and R. C. Schroter. Arterial wall shear and distribution of early atheroma in man. Nature 223:1159-1161, 1969.

${ }^{5}$ Chen, B. P., Y. S. Li, Y. Zhao, K.-D. Chen, S. Li, J. Lao, J. Y. Shyy, and S. Chien. DNA microarray analysis of gene expression in endothelial cells in response to $24 \mathrm{~h}$ shear stress. Physiol. Genomics 7:55-63, 2001.

${ }^{6}$ Constantinescu, A. A., H. Vink, and J. A. Spaan. Endothelial cell glycocalyx modulates immobilization of leukocytes at the endothelial surface. Arterioscler. Thromb. Vasc. Biol. 23:15411547, 2003.

${ }^{7}$ Cornelissen, A. J., J. Dankelman, E. VanBavel, and J. A. Spaan. Balance between myogenic, flow-dependent, and metabolic flow control in coronary arterial tree: A model study. Am. J. Physiol. Heart Circ. Physiol. 282:H2224-H2237, 2002.

${ }^{8}$ Cuff, C. A., D. Kothapalli, I. Azonobi, S. Chun, Y. Zhang, R. Belkin, C. Yeh, A. Secreto, R. K. Assoian, D. J. Rader, and E. Pure. The adhesion receptor CD44 promotes atherosclerosis by mediating inflammatory cell recruitment and vascular cell activation. J. Clin. Invest. 108:1031-1040, 2001.

${ }^{9}$ Davies, P. F. Flow-mediated endothelial mechanotransduction. Physiol. Rev. 75:519-560, 1995.

${ }^{10}$ Davies, P. F., A. Remuzzi, C. F. Dewey, E. J. Gordon, and M. A. Gimbrone Jr. Turbulent fluid shear stress induces vascular endothelial cell turnover in vitro. Proc. Natl. Acad. Sci. USA 83:2114-2118, 1986.

${ }^{11}$ Davies, P. F., C. F. Dewey, S. R. Bussolari, E. J. Gordon, and M. A. Gimbrone Jr. Influence of hemodynamic forces on vascular endothelial function: In vitro studies of shear stress and pinocytosis in cultured bovine aortic endothelial cells. J. Clin. Invest. 73:1121-1129, 1984.

${ }^{12}$ Davies, P. F., D. C. Polacek, C. Shi, and B. P. Helmke. The Convergence of hemodynamics, genomics, and endothelial struc- ture, in studies of the focal origin of atherosclerosis. Biorheology 39:299-306, 2002.

${ }^{13}$ Davies, P. F., M. A. Reidy, T. B. Goode, and D. E. Bowyer. Scanning electron microscopy in the evaluation of endothelial integrity of the fatty streak lesion of atherosclerosis. Atherosclerosis 25:125-130, 1976.

${ }^{14}$ DePaola, N., P. F. Davies, W. P. Pritchard, and D. Polacek. Spatial regulation of gap junction connexin 43 in endothelial cells exposed to disturbed flows in vitro. Proc. Natl. Acad. Sci. USA 96:3154-3160, 1999.

${ }^{15}$ Dewey, C. F., M. A. Gimbrone Jr., S. R. Bussolari, and P. F. Davies. The dynamic response of vascular endothelial cells to fluid shear stress. J. Biomech. Engineering 103:177-185, 1981.

${ }^{16}$ Friedman, M. H., O. J. Deters, C. B. Bargeron, G. M. Hutchins, and F. F. Mark. Shear-dependent thickening of the human arterial intima. Atherosclerosis 60:161-171, 1986.

${ }^{17}$ Fry, D. L., R. W. Mahley, K. H. Weisgraber, and S. Y. Oh. Simultaneous accumulation of Evans blue dye and albumin in the canine aortic wall. Am. J. Physiol. 233:H66-79, 1977.

${ }^{18}$ Garcia-Cardena, G., J. Comander, K. R. Anderson, B. R. Blackman, and M. A. Gimbrone. Biomechanical activation of vascular endothelium as a determinant of its functional phenotype. Proc. Natl. Acad. Sci. USA 98:4478-4485, 2001.

${ }^{19}$ Gimbrone, M. A., Jr., K. R. Anderson, J. N. Topper, B. L. Langille, A. W. Clowes, S. Bercel, M. G. Davies, K. R. Stenmark, M. G. Frid, M. C. Weiser-Evans, A. A. Aldashev, R. A. Nemenoff, M. W. Majesky, T. E. Landerholm, J. Lu, W. D. Ito, M. Arras, D. Scholz, B. Imhof, M. Aurrand-Lions, W. Schaper, T. E. Nagel, N., C. F. Dewey, and P. F. Davies. Special communication: The critical role of mechanical forces in blood vessel development, physiology and pathology. J. Vasc. Surg. 29:11041151, 2000.

${ }^{20}$ Glagov, S., E. Weisenberg, C. K. Zarins, R. Stankunavicius, and G. Kolettis. Compensatory enlargement of human atherosclerotic coronary arteries. N. Engl. J. Med. 316:1371-1375, 1987.

${ }^{21}$ Gnasso, A., C. Irace, C. Carallo, M. S. De Franceschi, C. Motti, P. L. Mattioli, and A. Pujia. In vivo association between low wall shear stress and plaque in subjects with asymmetrical carotid atherosclerosis. Stroke 28:993-998, 1997.

${ }^{22}$ Govers, R., and T. J. Rabelink. Cellular regulation of endothelial nitric oxide synthase. Am.J. Physiol. Renal. Physiol. 280:F193206, 2001.

${ }^{23}$ Hacking, W. J. G., E. VanBavel, and J. A. E. Spaan. Shear stress is not sufficient to control growth of vascular networks: A model study. Am. J. Physiol. 270:H364-H375, 1996.

${ }^{24}$ Hajra, L., A. I. Evans, M. Chen, S. J. Hyduk, T. Collins, and M. I. Cybulsky. The NF-kappa B signal transduction pathway in aortic endothelial cells is primed for activation in regions predisposed to atherosclerotic lesion formation. Proc. Natl. Acad. Sci. USA 97:9052-9057, 2000.

${ }^{25}$ Helmke, B. P., A. B. Rosen, and P. F. Davies. Mapping mechanical strain of an endogenous cytoskeletal network in living endothelial cells. Biophys. J. 84: 2691-2699, 2003.

${ }^{26}$ Helmke, B. P., D. Thakker, R. D. Goldman, and P. F. Davies. Quantitative spatial analysis of flow-induced intermediate filament displacement in living endothelial cells. Biophys. J. 80:184-194, 2001.

${ }^{27}$ Honda, H. M., T. Hsiai, C. M. Wortham, M. Chen, H. Lin, M. Navab, and L. L. Demer. A complex flow pattern of low shear stress and flow reversal promotes monocyte binding to endothelial cells. Atherosclerosis 158:385-390, 2001.

${ }^{28}$ Hsiai, T. K., S. K. Cho, P. K. Wong, M. Ing, A. Salazar, A. Sevanian, M. Navab, L. L. Demer, and C. M. Ho. Monocyte 
recruitment to endothelial cells in response to oscillatory shear stress. Faseb J. 17:1648-1657, 2003.

${ }^{29}$ Hull Jr., S. S., L. Kaiser, M. D. Jaffe, and H. V. Sparks Jr. Endothelium-dependent flow-induced dilation of canine femoral and saphenous arteries. Blood Vessels. 23:183-198, 1986.

${ }^{30}$ Kamiya, A., R. Bukhari, and T. Togawa. Adaptive regulation of wall shear stress optimizing vascular tree function. Bull. Math. Biol. 46:127-137, 1984.

${ }^{31}$ Khayutin, V. M., A. M. Melkumyants, A. N. Rogoza, E. S. Veselova, S. A. Balashov, and V. P. Nikolsky. Flow-induced control of arterial lumen. Acta Physiol. Hung. 68:241-251, 1986.

${ }^{32}$ Krams, R., J. J. Wentzel, J. A. Oomen, R. Vinke, J. C. Schuurbiers, P. J. de Feyter, P. W. Serruys, and C. J. Slager. Evaluation of endothelial shear stress and $3 \mathrm{D}$ geometry as factors determining the development of atherosclerosis and remodeling in human coronary arteries in vivo. Combining 3D reconstruction from angiography and IVUS (ANGUS) with computational fluid dynamics. Arterioscler. Thromb. Vasc. Biol. 17:2061-2065, 1997.

${ }^{33}$ Ku, D. N., D. P. Giddens, C. K. Zarins, and S. Glagov. Pulsatile flow and atherosclerosis in the human carotid bifurcation. Positive correlation between plaque location and low and oscillating shear stress. Arteriosclerosis 5:293-301, 1985.

${ }^{34}$ Kuo, L., W. M. Chilian, and M. J. Davis. Interaction of pressureand flow-induced responses in porcine coronary resistance vessels. Am. J. Physiol. 261:H1706-H1715, 1991.

${ }^{35}$ Langille, B. L., and F. O'Donnel. Reductions in arterial diameter produced by chronic decreases in blood flow are endotheliumdependent. Science 231:405-407, 1986.

${ }^{36}$ Levesque, M. J., and R. M. Nerem. The elongation and orientation of cultured endothelial cells in response to shear stress. J. Biomech. Eng. 107:341-347, 1985.

${ }^{37}$ Malek A. M., and S. Izumo. Control of endothelial cell gene expression by flow. J. Biomech. 28:1515-1528, 1995.

${ }^{38}$ Murray, C. D. The physiological principle of minimum work. I. The vascular system and the cost of blood volume. Proc. Natl. Acad. Sci. 12:207-214, 1926.

${ }^{39}$ Olesen, S. P., D. E. Clapham, and P. F. Davies. Hemodynamic shear stress activates a $\mathrm{K}+$ current in vascular endothelial cells. Nature 331:168-170, 1988.

${ }^{40}$ Passerini, A. G., D. C. Polacek, C. Shi, N. M. Francesco, E. Manduchi, G. Grant, W. P. Pritchard, S. J. Powell, G. Chang, C. Stoeckert, and P. F. Davies. Coexisting pro-inflammatory and anti-oxidative endothelial transcription profiles in a disturbed flow region of the adult porcine aorta. Proc. Natl. Acad. Sci. USA 101:2482-2487, 2004.

${ }^{41}$ Pohl, U., K. Herlan, A. Huang, and E. Bassenge. EDRFmediated shear-induced dilation opposes myogenic vasoconstriction in small rabbit arteries. Am. J. Physiol. 261:H2016H2023, 1991.

${ }^{42}$ Polacek, D. C., A. Passerini, C. Shi, N. M. Francesco, E. Manduchi, G. Grant, S. J. Powell, H. Bischof, H. Winkler, C. Stoeckert, and P. F. Davies, Fidelity and enhanced sensitivity of differential transcription profiles following linear amplification of nanogram amounts of endothelial mRNA. Physiol. Genomics 13:147-156, 2003.

${ }^{43}$ Pries, A. R., T. W. Secomb, P. Gaehtgens, and J. F. Gross. Blood flow in microvascular networks. Experiments and simulation. Circ. Res. 67:826-834, 1990.
${ }^{44}$ Pries, A. R., T. W. Secomb, and P. Gaehtgens. Design principles of vascular beds. Circ. Res. 77:1017-1023, 1995.

${ }^{45}$ Remuzzi, A., C. F. Dewey, P. F. Davies, and M. A. Gimbrone Jr. Orientation of endothelial cells in shear fields in vitro. Biorheology 21:617-630, 1984.

${ }^{46}$ Resnick, N., H. Yahav, L. M. Khachigian, T. Collins, K. R. Anderson, F. C. Dewey, and M. A. Gimbrone Jr. Endothelial gene regulation by laminar shear stress. Adv. Exp. Med. Biol. 430:155-164, 1997.

${ }^{47}$ Schretzenmayr, A. Ueber kreislaufregulatorische vorgange an den groben arterien bei der muskelarbeit. Pflügers Archiv 232:743-748, 1933.

${ }^{48}$ Shyy, J. Y., and S. Chien. Role of integrins in cellular responses to mechanical stress and adhesion. Curr. Opin. Cell. Biol. 9:707713, 1997.

${ }^{49}$ Tzima, E., W. B. Kiosses, M. A. del Pozo, and M. A. Schwartz. Localized cdc42 activation, detected using a novel assay, mediates microtubule organizing center positioning in endothelial cells in response to fluid shear stress. J. Biol. Chem. 278:3102031023, 2003.

${ }^{50}$ Van den Berg, B. M., H. Vink, and J. A. Spaan. The endothelial glycocalyx protects against myocardial edema. Circ. Res. 92:592-594, 2003

${ }^{51}$ Van Haperen, R., C. Cheng, B. M. Mees, E. van Deel, M. de Waard, L. C. van Damme, T. van Gent, T. van Aken, R. Krams, D. J. Duncker, and R. de Crom. Functional expression of endothelial nitric oxide synthase fused to green fluorescent protein in transgenic mice. Am. J. Path. 163:16771686, 2003.

${ }^{52}$ Wasserman, S. M., F. Mehraban, L. G. Komuves, R. B. Yang, J. E. Tomlinson, Y. Zhang, F. Spriggs, and J. N. Topper. Gene expression profile of human endothelial cells exposed to sustained fluid shear stress. Physiol. Genomics 12:1323, 2002.

${ }^{53}$ Wentzel, J. J., R. Krams, J. C. Schuurbiers, J. A. Oomen, J. Kloet, W. J. van Der Giessen, P. W. Serruys, and C. J. Slager. Relationship between neointimal thickness and shear stress after Wallstent implantation in human coronary arteries. Circulation 103:1740-1745, 2001.

${ }^{54}$ Wentzel, J. J., F. J. Gijsen, N. Stergiopulos, P. W. Serruys, C. J. Slager, and R. Krams. Shear stress, vascular remodeling and neointimal formation. J. Biomech. 36:681-688, 2003.

${ }^{55}$ Wentzel, J. J., D. M. Whelan, W. J. van der Giessen, H. M. van Beusekom, I. Andhyiswara, P. W. Serruys, C. J. Slager, and R. Krams. Coronary stent implantation changes 3-D vessel geometry and 3-D shear stress distribution. J. Biomech. 33:1287-1295, 2000.

${ }^{56}$ Vink, H., and B. R. Duling. Identification of distinct luminal domains for macromolecules, erythrocytes, and leukocytes within mammalian capillaries. Circ. Res. 79:581-589, 1996.

${ }^{57}$ Worth Longest, P., and C. Kleinstreuer. Comparison of blood particle deposition models for non-parallel flow domains. J. Biomech. 36:421-430, 2003.

${ }^{58}$ Zarins, C. K., D. P. Giddens, B. K. Bharadvaj, V. S. Sottiurai, R. F. Mabon, and S. Glagov. Carotid bifurcation atherosclerosis. Quantitative correlation of plaque localization with flow velocity profiles and wall shear stress. Circ. Res. 53:502$514,1983$. 